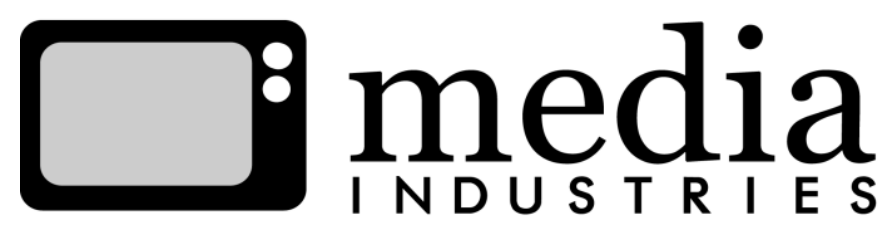

\title{
Cultural Diversity as Brand Management in Cable Television
}

\author{
Melanie E. S. Kohnen ${ }^{1}$
}

melanieeskohnen [AT] gmail.com

\begin{abstract}
:
This article explores the strategic use of cultural diversity as brand management tool in cable television via the case study of The Fosters, a prime-time soap on ABC Family. Specifically, I examine three interrelated facets of The Fosters and its industrial context, namely the program's representation of meaningful cultural diversity, how this meaningful diversity functions as a strategy for ABC Family's brand of "A New Kind of Family," and how media scholars can make sense of a discourse of diversity imbricated in corporate brand management. Instead of dismissing branded diversity, I argue that we should closely examine it to recognize the possibilities and constraints of culturally diverse representations emerging out of and enabled by television brand management.
\end{abstract}

Keywords: Audiences, Branding, Cable, Distribution, Race

Imagine the following TV program: a family drama about an interracial lesbian couple raising a multiethnic group of children in which the plot explicitly addresses the following issues: racial and ethnic difference, sexuality and gender, class, and the failure of institutions, especially the foster care system. This program embodies the kind of meaningful diversity for which media scholars frequently ask, but it seems utopian to imagine such a drama would appear on American television. Yet this program exists. It is called The Fosters (2013-) and airs on the Disney-owned cable channel ABC Family. Using The Fosters as a case study, this article explores the strategic use of cultural diversity as brand management tool in cable television. Specifically, I examine three interrelated facets of The Fosters and its industrial context. First, I analyze the program's representation of meaningful cultural diversity. According to Mary Beltrán, meaningful diversity in television occurs when characters of color move beyond token status and appear as complex people with rich interiority and the agency to drive the narrative forward. ${ }^{2}$ Second, I demonstrate how this meaningful diversity functions as a strategy for ABC Family's brand of "A New Kind of Family," turning it into what I call branded diversity. I use "branded diversity" to describe the inclusion of cultural diversity in television programming that is motivated by and contributes to a channel's branding strategies. Finally, I examine how media scholars can make sense of diversity imbricated in corporate brand management via a few examples of how meaningful and branded diversity overlap in The Fosters. Instead of dismissing branded diversity, I argue that we should closely examine it to recognize the 
possibilities and constraints of emerging culturally diverse representations enabled by television brand management. Even though the inclusion and direct address of cultural diversity on The Fosters is motivated by corporate interests, it nevertheless constitutes an important contribution to the representation of intersectional identities on television.

This article thus also addresses the question of where meaningful representations of diversity can happen in the mainstream media. In the case of The Fosters, this holds particularly true for the representation of the central lesbian couple. The inclusion of LGBTQ (lesbian, gay, bisexual, transgender, queer, and questioning) characters and stories as a quotidian occurrence in film and television often leads to a reduction and constraint of what queer visibility can be, but not on The Fosters. Despite the various demands placed on the program by its genre, the necessity to further ABC Family's brand, and its appeal to a young adult audience, it delivers a representation of a meaningfully diverse family that challenges established LGBTQ tropes and offers a deeper engagement with racial diversity than many so-called "quality television" programs on channels like $\mathrm{HBO}$ and AMC.

\section{Meet the Fosters and ABC Family}

The Fosters premiered on ABC Family in the summer of 2013 and has aired three seasons to date. The program was created by Bradley Bredeweg and Peter Paige, both of whom identify as gay and who have significant experience in television. (Peter Paige is probably best known for his role as Emmett Honeycutt in the American production of Queer as Folk, 2000-2005.) Jennifer Lopez joined The Fosters as an executive producer. During an interview on Ellen DeGeneres's daytime talk show, Lopez explained that she produces the show in memory of a gay aunt with whom she grew up and admired. ${ }^{3}$ Lopez also emphasized that the Fosters are "just another family," using the common strategy of highlighting sameness between straight and gay communities, rather than difference, to make LGBTQ representations palatable to a mainstream audience. ${ }^{4}$ But the Fosters are not like all other (television) families because they offer a complex view of life in a diverse family. While many current family dramas include at least some racial, ethnic, and sexual diversity in their cast of characters, this diversity is often a veneer - there to be looked at, but not to be explored. Indeed, many seemingly diverse programs with ensemble casts only feature people of color in supporting roles and direct the viewers' attention toward the white protagonists. ${ }^{5}$ In contrast, The Fosters offers what Beltrán has termed "meaningful diversity;" its characters of color are "fully realized individuals" with interiority and agency created by writers who seem to understand the communities with which the characters are affiliated. ${ }^{6}$ Moreover, the diversity of the cast connects meaningfully to the setting: the city or region in which the program takes place. While race and sexuality are overlapping yet different discourses, the idea of meaningful diversity can also be applied to the representation of sexuality when considering tropes specific to LGBTQ representation on television. One might ask whether LGBTQ characters are fully realized individuals, for example, and whether their intimate relationships receive the same attention as those of straight characters. With a higher than usual degree of diversity among the writing staff, this certainly seems to be the case on The Fosters. ${ }^{7}$ The diversity in the writers' room not only enhances the program's meaningful diversity but also allows the show to be promoted as having an authentic voice, which benefits ABC Family's brand.

Indeed, in interviews and on social media, the writers connect their own experiences to characters' lives, thus lending credibility to both channel and program brand. 


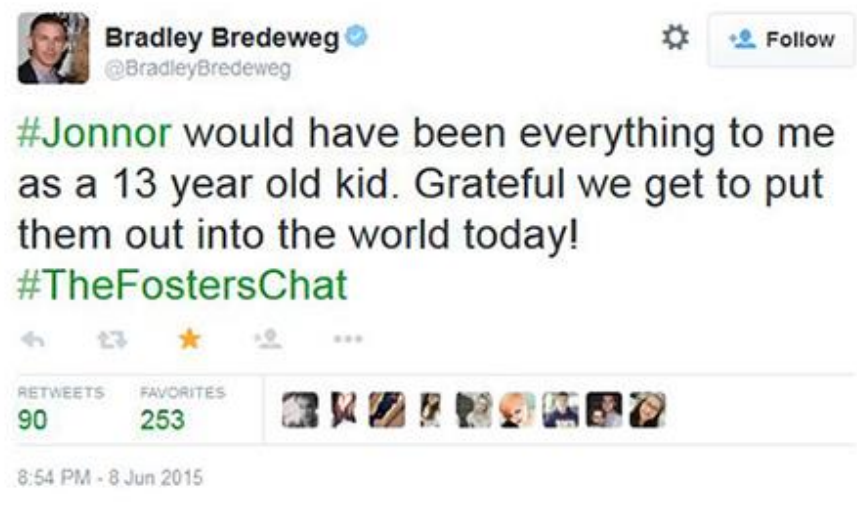

Figure 1. Showrunner Bradley Bredeweg comments on the developing relationship between "Jonnor" (Jude Foster and Connor Stevens), two teen boys on The Fosters.

A brief introduction of the central characters and storylines offers an insight into the construction of meaningful diversity on The Fosters. The program is set in San Diego and centers on the lives of Stef Foster (Teri Polo), Lena Adams (Sherri Saum), and their five teenage children. While Stef's racial background is not overtly discussed, she appears to be white. Stef is an officer with the San Diego Police Department and works with her ex-husband, Mike (Danny Nucci). Her partner Lena is identified as biracial, the daughter of a black woman and a white man.

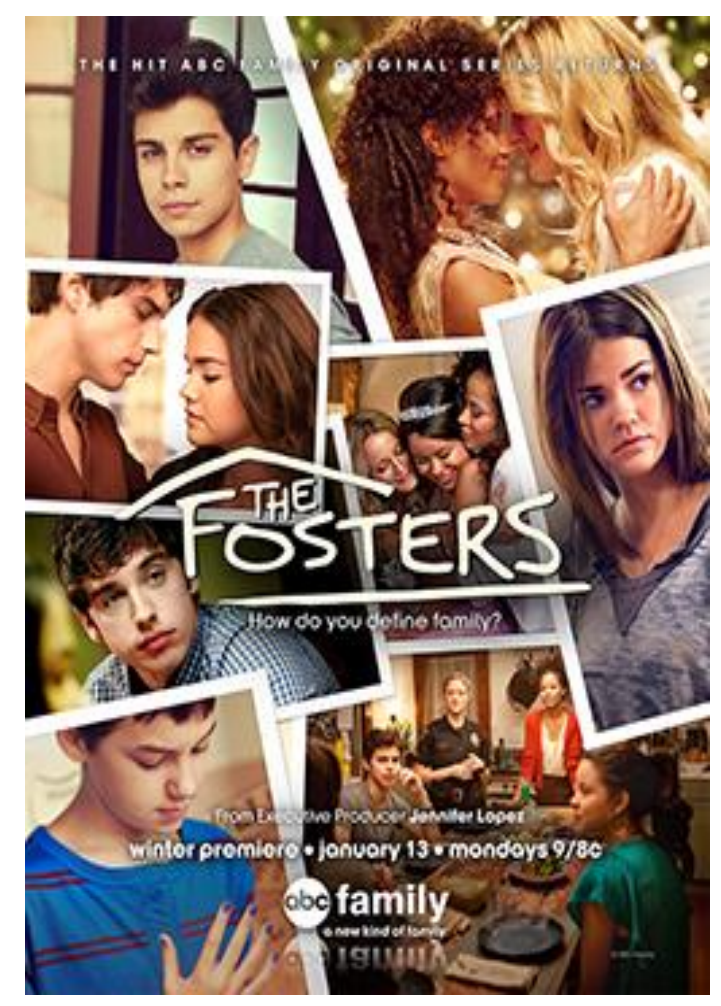

Figure 2. ABC Family promotional picture of The Fosters, season 1.

Lena's biracial identity is discussed in various recurring storylines. Lena is the vice principal of the charter school that all her children attend. Stef and Lena share custody of Brandon (David 
Lambert), Stef's son from her previous marriage. Stef and Lena's relationship, including how they met and Stef's coming out, is explored throughout the first season. Mariana (Cierra Ramirez) and Jesus (Jake T. Austin) are twins who were adopted by Stef and Lena when they were five years old. The potential for friction arising out of parents raising children from a different cultural background appears throughout the first season, especially in the episode "Quinceañera," which I will examine in more detail below. Callie (Maia Mitchell) and Jude (Hayden Byerly), sister and brother, are the latest additions to the family. They are also signified as white, mostly due to an absence of any references to their racial identity. They become Stef and Lena's foster children in the pilot, and their presence in the program allows for a critique of the foster care system, as Callie and Jude moved through various foster families before ending up with Stef and Lena. The diversity of the family appears in tune with the setting of San Diego, especially via Mariana and Jesus, whose Latino/a identity is the focal point of several episodes. Overall, The Fosters offers meaningful diversity by providing viewers with insights into all the family members, who take turns being the focal points of episodes. Moreover, the program overtly addresses what it means to be a part of a diverse, nontraditional family and explores identity formation as an ongoing process.

The inclusion of meaningful cultural diversity on The Fosters is directly related to and an outcome of ABC Family's branding and programming strategies. Indeed, one cannot understand the full significance of diversity on The Fosters without examining the industrial context of the program. According to ABC Family's 2012 "Fact Sheet," the cable channel "features programming reflecting today's families, entertaining and connecting with adults through relatable stories about today's relationships, told with a mix of diversity, passion, humor and heart" and caters to a millennial audience. ${ }^{8}$ The phrase "programming reflecting today's families" is of particular significance to The Fosters - this is the type of contemporary family that $\mathrm{ABC}$ Family imagines its target millennial audience will find "relatable." The phrase "diversity, passion, humor, and heart" frequently appears in trade press articles about ABC Family, underlining the centrality of diversity to the channel's brand. ${ }^{9}$

This latest reiteration of ABC Family is far removed from the channel's conservative origins as part of Pat Robertson's Christian Broadcast Network (CBN). Founded in 1977, it remained part of CBN until 1998, when it was sold to NewsCorp and renamed Fox Family. Disney acquired the channel in 2001 and renamed it ABC Family. It muddled along with a conservative legacy and a desire to appeal to younger audiences until 2007, when Disney decided to tailor the channel specifically to millennials, the name assigned to the generation of people born between 1976 and 1996. This rebranding strategy draws on research by the media consulting agency Frank N. Magid Associates and insights drawn from Millennials Rising, by William Strauss and Neil Howe, an influential book for defining the millennial generation. ${ }^{10}$ In 2007, a multipage Ad Age special feature called "Getting to Know the Millennials" introduced the newly rebranded ABC Family and its perception of millennial audiences. A section of "millennial facts" characterizes this generation as diverse, engaged with social media, educated, and family- and community-oriented.11 It also includes a projection that this generation will make up 50 percent of the coveted eighteen-to-forty-nine demographic by 2010, which conveyed to advertisers the desirability and necessity of targeting this group. As a channel catering to millennials, ABC Family portrays itself as a particularly appealing gateway to this demographic for advertisers.

At the center of the Ad Age special is a continuous emphasis on the importance of family to millennials. Consider the following statement by John Rood, senior vice president of marketing: 
We learned that Millennials value their families. As a network called ABC Family, that was music to our ears. We realized through our research that it wasn't that America's young adults had a problem with family; it is that they had a problem with family television - specifically the stereotypical conservative, boring or insincere aspects of family television. ${ }^{12}$

There are a few important insights to be gained from this brief statement. First, Rood emphasizes that ABC Family's research revealed that millennials value family-oriented television when it transcends the genre's stereotypes. While Rood portrays this insight as a discovery and perhaps a happy coincidence for his channel, one has to keep in mind that the word family is required to be in the name of the channel, a precondition that dates back to the channel's origins. ${ }^{13}$ This requirement likely contributed to ABC Family executives' embrace of a millennial audience that can be constructed as big believers in families and in family-oriented television. As Julia Himberg observes regarding cable channel branding, "the first objective is to establish the [channel] brand's strength by finding where its defining features overlap with perceived consumer needs and competitor weakness." 14 In the case of ABC Family, the millennial-oriented rebranding matches its defining feature of being oriented toward families in some way due to the residual naming requirement. Likewise, this focus on families allows the channel to provide millennials with the type of family television they supposedly desire: programming that is not "conservative, boring or insincere." In portraying millennials as a demographic that desires family-oriented programming, ABC Family defines not only its brand but also a generation. After all, as Louisa Stein has argued, the idea of the millennial generation is largely discursive, constructed by materials such as the Ad Age feature on ABC Family. ${ }^{15}$ In other words, the Ad Age special feature creates ABC Family's millennial audience as much as it describes it. In so doing, ABC Family follows previous successful examples, including Nickelodeon, which managed to constitute a generation of kids as consumer citizens through its message of empowerment. ${ }^{16}$ ABC Family thus defines millennials as a generation that appears as a perfect match for its brand and its advertisers.

The Ad Age special also outlines what kinds of programming millennials desire. As John Rood points out, millennials reject "stereotypically conservative" programming. ABC Family's tagline "a new kind of family" signals that their programming will not be focused on traditional family values. Analyzing the channel's rebranding, Ad Age's Nancy Giges explains that then-ABC Family president Paul Lee "wanted to clarify the definition of family, reclaiming it from those who had hijacked it for political and religious reasons and defining it for what it really is." 17 From this point of view, ABC Family reclaims family from the channel's conservative roots. ABC Family, its programming, and its imagined millennial audience all value family, but this family is not the nuclear, white, Christian family of television's past but rather an ethnically and racially diverse family that may include same-sex parents. ABC Family's branding strategy thus courts an imagined young millennial audience invested in both familial bonds and cultural diversity. This strategy imagines diversity in terms of how the generation of millennials is constituted - they are a culturally diverse group - and how this generation approaches media consumption-millennials expect diversity in their TV programming as a matter of course. While ABC Family's open defiance of "family values" seems like a risky strategy, it builds on years of careful planning (the Ad Age special points to four years of research), previous successful examples (like Nickelodeon), and a corporate strategy that is typical of Disney. ${ }^{18}$ Early hits Kyle XY (2006-2009) and The Secret Life of the American Teenager (2008-2013) affirmed the rebranding decision through their success with millennials. 
The Fosters perfectly embodies the "new kind of family" brand: it offers a nontraditional family that embraces traditional family values. This combination comes through the best in the program's credit sequence, which pairs snapshots of peaceful domesticity with a song that states: "It's not where you come from / it's where you belong."

Much as the Fosters choose to be a family, ABC Family wants millennials to imagine that they belong to the channel's "new kind of family." This invitation to join the family is facilitated through social media. Like all other ABC Family programs, The Fosters has active Twitter, Tumblr, Facebook, and Instagram accounts, all of which are updated every day with new content while the program is on the air.

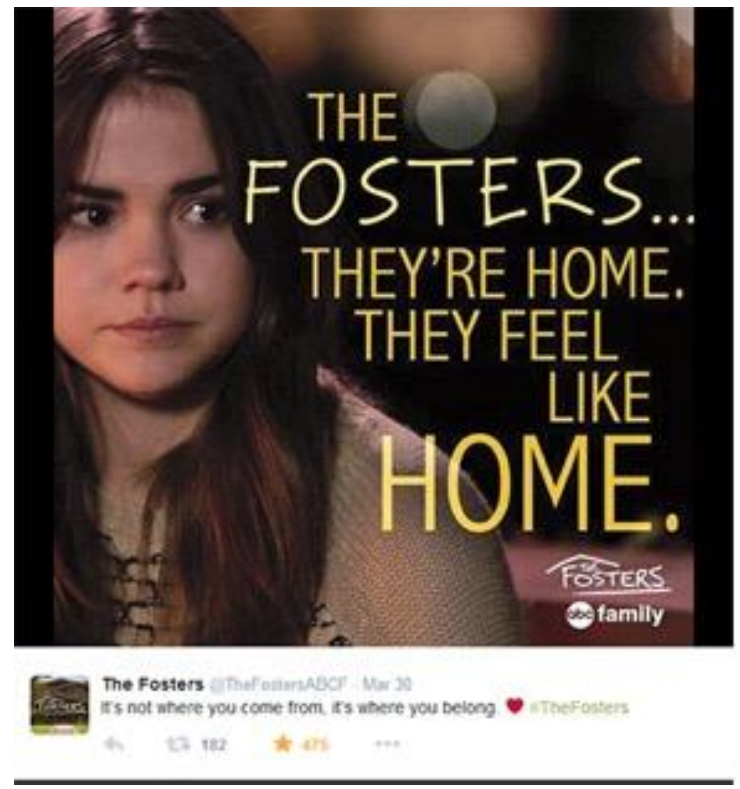

Figure 3. Example of a typical tweet from the official The Fosters Twitter account, posted March 30, 2015. The image invites viewers to feel like they are part of the Foster family while the words cite the lyrics from The Fosters's theme song.

Most tweets and updates share sneak peeks of the following week's episode or ask viewers what they thought of key moments during the preceding episode. Actors share anecdotes and pictures from the set and their lives via social media; they also emphasize that the cast members share close bonds, suggesting that they are a family themselves. These constant updates and invitations to participate keep viewers engaged with the program even when it is off the air. During both the East and West Coast airings of new episodes, the official Twitter account and the actors live-tweet, offering their insights on the episode and answering viewers' questions. Viewers are also asked to use specific hashtags that appear on screen during select scenes. This multiplatform social media strategy aims to create brand loyalty and allows the channel to track viewers' reactions. Viewers respond in a largely positive way to these official invitations to participate, but it is important to note that they also create their own content circulating on Tumblr and Twitter, which is often recirculated by the official The Fosters accounts. While this back-and-forth between viewers and creators is not unusual in contemporary television, ABC Family was one of the first channels to make social media a cornerstone of brand and viewer engagement. The 2007 Ad Age feature introducing the rebranded channel already discusses the 
significance of multiplatform content and mobile media at a time when Twitter was still in its infancy (the platform launched in 2006).

In both official and fan-made content, diversity plays a central role. Tweets often feature the hashtag \#loveislove in support of Stef and Lena's relationship in particular and the LGBTQ community in general. Fans also comment on The Fosters's engagement with racial-ethnic identity formation and questions of belonging. Consider the following Tumblr post about Mariana's decision to dye her hair blonde to better fit in with her all-white dance team, which received over three hundred notes of support: "Can we talk about how The Fosters continues to tackle colorism and inter- as well as intra-racial issues. ... I love this show because it is tackling these issues in ways that are subtle but powerful."19 These kind of comments show that diversity on The Fosters is meaningful not only in the context of theories of media representation but also to viewers of the program.

\section{Understanding Branded Diversity}

The integration of diversity in a branding strategy is not new or unique to ABC Family, but the type of diversity represented on The Fosters differs from other strategic uses in its willingness to address institutional and personal struggles with identity formation and familial belonging. Traditionally, one of the defining characteristics of cable channels is the appeal to a particular demographic or the focus on a specific type of programming (as on Comedy Central or the History Channel). Important to note here is the difference between cable channels that target particular demographic groups defined by race, ethnicity, gender, or sexuality-such as BET, Univision, Lifetime, or Logo (in its early days)-and channels like ABC Family and Nickelodeon. For BET and similar channels, the incorporation of particular articulations of diversity in their brand and programming is a given. ${ }^{20}$ In contrast, ABC Family, like Nickelodeon before it, targets a particular generation and uses diversity as one core feature of its brand to attract that particular group to its programming. ${ }^{21}$ Sarah Banet-Weiser's analysis of Nickelodeon in Kids Rule! Nickelodeon and Consumer Citizenship is particularly instructive for understanding diversity as a branding strategy. Banet-Weiser argues that Nickelodeon differentiates its brand from other cable channels "in how it 'empowers' children through (among other things) the commitment to gender and ethnic representation." 22 Similarly, ABC Family portrays itself as a destination for millennials through a representation of diverse families and an audience address that invites viewers to become part of its "new kind of family." In the case of Nickelodeon, a branded and tightly managed version of diversity emerges that is often rendered palatable by avoiding overt social critique. As examples of this type of branded diversity, Banet-Weiser mentions the inclusion of nonspecific ethnic and racial identities and the celebration of cultural heritage in programs that do not raise issues such as lingering institutionalized racism, dwindling support for education, and immigration issues. ${ }^{23}$ Similar strategies for including diversity also appear in ABC Family's programming, for example in Switched at Birth. At the same time, a more profound engagement with diversity appears on The Fosters, where racial, ethnic, and sexual difference is openly addressed.

While ABC Family engages with a wide spectrum of diversity in its brand and programming, The Fosters and the channel in general have received much popular press praise for the inclusion of sexual diversity in particular. ${ }^{24}$ The inclusion of LGBTQ characters in its vision of "a new kind of family" is the most explicit challenge to traditional family values and thus a core aspect of the channel's brand. Once again, there are precedents for the strategic incorporation of LGBTQ representation to further a network or channel brand. Ron Becker's discussion of 
network TV's courting of "slumpies" (socially liberal, urban-minded professionals) via gaythemed programming in the 1990s is particularly relevant.25 Under the increasing pressure of cable TV's success, the networks began to include gay and lesbian characters to create "edgy" programming aimed at the coveted "slumpy" demographic. Becker argues that LGBTQ representations in '90s network programming barely exceed tokenism and were circumscribed by a number of factors: gay and lesbian characters often appeared only in supporting roles, were rarely represented in meaningful intimate relationships, were isolated from LGBTQ communities, and were mostly white. ${ }^{26}$ While the inclusion of gay and lesbian characters has become a routine element of television programming, many of these limitations, especially regarding whiteness and intimacy, still apply to LGBTQ representations on TV, particularly on network television. The Fosters moves beyond many of these limitations by placing an interracial lesbian couple at the center of its narrative, which I take as an indication that while the incorporation of diversity on ABC Family programming is certainly strategic, it also moves beyond tokenism and toward the meaningful inclusion of gay and lesbian characters.

The strategic use of LGBTQ content to signify edginess has not disappeared. Regarding the inclusion of lesbian programming in cable channels including Bravo and Showtime, Himberg observes that it "has emerged as a significant method for creating 'edgy' programming and attracting a wide range of viewers to cable TV." 27 Himberg calls this strategy "multicasting" and argues that it is a "calculated approach to attracting audiences to cable programming based on demographics constructed and refined by market research." 28 In order to reach those audience segments, Bravo and Showtime weave a gay sensibility into their programming but do not include social critique or even direct direct discussion of sexual identity. ${ }^{29}$ While both the "slumpy" approach and the multicasting tactic use gay and lesbian characters in an indirect way-where these tactics are nearly disavowed by executives in the case of Bravo and Showtime-ABC Family is upfront about diversity, including diverse representations of sexuality, as a core feature of the brand (recall that diversity is routinely included in official publicity materials to characterize ABC Family programming). ABC Family's strategic use of diversity is also based on market research, but its inclusion of LGBTQ characters is not about "edginess." Rather, it is about capturing the "real" experiences of millennials (as articulated by ABC Family's vision of this generation). In addition, in addressing itself to millennials, ABC Family does not multicast so much as it seeks a broad, yet also precisely defined, audience that encompasses viewers from different cultural backgrounds and stages of life.

Once again, we can see a parallel between ABC Family's inclusion of diversity and earlier strategies used by Nickelodeon, whose executives also explain the inclusion of diversity as a desire to reflect kids' "real" lives. For Banet-Weiser, this appeal to realism leads to an ambivalent engagement with diversity. By portraying diversity as simply "being there" in kids' lives, Nickelodeon includes diversity in much the same way in its programs: it is there but not discussed. As such, it renders the political potential of these programs moot, argues BanetWeiser. ${ }^{30}$ There are certainly reasons to feel ambivalent about ABC Family's strategic use of diversity to further its brand, even if programs like The Fosters critically engage with diverse identities by interrogating the process of identity formation and acknowledging the difficulties that come with it. Banet-Weiser seems to feel ambivalent about the corporate version of diversity offered by Nickelodeon and, in her more recent work, about the advancement of branding into most areas of life. ${ }^{31}$ Indeed, scholars frequently find articulations of diversity that are deeply imbricated in corporate strategies to be of ambivalent value at best, championing independent media productions and their engagements with diversity over their mainstream 
counterparts. For example, both political economists and scholars who study queer media representations offer skeptical analyses of mainstream attempts of engaging with diversity. In the conclusion to New Queer Cinema: The Director's Cut, B. Ruby Rich explains that the proliferation of LGBTQ images on TV in the 2000s deserves recognition, but she ultimately concludes, "The price of all that mainstreaming on television was the demise of the boundarypushing, ideology-challenging New Queer Cinema. Who needed NQC once TV delivered its cuddlier version to networks and cable stations?" 32 Rich implies that, in contrast with independent film, TV can only deliver "cuddly" versions of queer representations that are necessarily devoid of critical potential due to their mainstream production context. Similarly, political economists like Robert McChesney believe that institutional constraints of the media industry make it difficult to produce media that offers creative plots, let alone social critique. ${ }^{33}$ Nevertheless, texts such as The Fosters and their relationship to cable television branding are important, and not only as negative examples. I think it is possible for media scholars to embrace diversity imbricated in corporate branding. As Lisa Henderson argues in Love and Money: Queers, Class, and Cultural Production, it is important to recognize the limitations of mainstream media production but not to see them as all-encompassing. ${ }^{34}$

In chapter 5 of her book, Henderson discusses the relationship between independent queer film and mainstream film. Instead of seeing stark oppositions - not-for-profit radical queer versus commercialized nonqueer media texts-she proposes the recognition of a wider field of exchanges. She asks, "What would a different critique look like? One whose primary move is not to rush in with self-preserving refusal at the first or last sign of queer encounter with nonqueer market culture?" 35 A critique building on this concept recognizes "an ongoing, uneven process of cultural passing off, catching, and passing on" 36 between independent and mass media or, in the case of The Fosters, between meaningful diversity and branding strategies. Instead of snapping to a paranoid position of rigidly drawn lines, Henderson proceeds with an analysis that recognizes the homonormative impulses of mainstream media production but refuses to see them as ending all potential for diverse representation. Most importantly, she reveals the elitist underpinnings of instantly refusing mainstream media. A rejection of commercialized media on the part of queer cultural critics is meant as a protective gesture to preserve the independence of queer voices. However, this rejection can serve to sustain cultural hierarchies and class lines because it implicitly reaffirms the idea that commercial media by default caters to the lowest common denominator of popular tastes and is thus incapable of offering social critique. ${ }^{37}$ Henderson argues that this longstanding denigration of commercial pop culture fails to recognize the struggles for a queer presence within mainstream media. I agree with Henderson and want to recognize The Fosters as a noteworthy presence of queer and ethnic diversity in today's television landscape. In the following section, I analyze several storylines that both closely fit into ABC Family's brand and create a space for meaningful diversity.

\section{Branded Diversity on The Fosters}

The majority of storylines on The Fosters revolve around conflicts arising from personal relationships. Considering that the program is best classified as a prime-time soap, this focus on the personal and the familial is not surprising. Many plots on The Fosters are staples of soaps, especially those that also draw on teen drama: peer pressure, first love, dating, parent-child tension, and so forth. The generic affiliation with the soap also allows the program to explore personal and interpersonal issues in greater depth than a prime-time drama focused on a season-long mystery or an episodic procedural. The Fosters's critical engagement with diversity 
also connects to its status as a soap, as this genre has long been a space for broaching social issues that received less or no attention in more "quality" programs. ${ }^{38}$ Indeed, The Fosters's genre fits perfectly with ABC Family's brand: the soap's strong focus on personal relationships provides the space in which "a new kind of family" can emerge.

Mariana's quinceañera is a key moment in the first season in which cultural identity and familial bonds come into conflict. In "Quinceañera," the opening scene sets up the conflict that unfolds throughout the episode. Mariana, her friend Lexi (Bianca A. Santos), and Lena are dress shopping for the quinceañera. While trying on a dress, a sales assistant asks Mariana in Spanish whether her father's tie is going to match her dress for the father-daughter dance. This seemingly unremarkable question places Mariana in an awkward position. First, Lexi has to translate the question since Mariana does not seem to be fluent in Spanish, marking her as an outsider to the easy back-and-forth between Lexi and the sales associate and, by wider association, to the Latino/a community. In addition, the revelation that Mariana has two moms clearly surprises the sales associate, leading her to suggest that Mariana could dance with a male relative. The implication here is that the tradition of the father-daughter dance-and perhaps Latino/a culture at large-does not have room for a family arrangement like Mariana's. Lexi insists that Mariana will dance with her moms as a matter of course, but Mariana remains silent. When Lexi later mentions to Mariana that she would like to have two mothers because her own parents refused to throw her a quinceañera party, she adds, "And we're Latino! I mean, so are you, but you know what I mean." Lexi's statement articulates the conflict Mariana experiences in this episode most clearly. Mariana identifies as Latina, but she was not raised as part of the Latino/a community. Moreover, Mariana's uncertainty about the father-daughter dance suggests that she feels an additional degree of alienation as the daughter of a lesbian couple. The quinceañera is a way for her to claim a way of belonging to this community, but this undertaking is not without complications. Mariana ends up dancing with Mike, Stef's ex-husband and family friend. While she seems to enjoy herself, the episode concludes with Mariana's emotional apology to Stef and Lena, explaining that she should have danced with them because they are "the best moms in the world." The three of them return to the dance floor as the party winds down, allowing Mariana to adapt the father-daughter dance to her family situation and to confirm, in the words of The Fosters's credits, that "it is not where you come from [i.e., being born to a Latina mother] / it is where you belong [i.e., a culturally mixed, nontraditional family]." While this happy ending might seem like an overly facile resolution to a complex subject, the episode acknowledges the difficulty of figuring out where one belongs, culturally and familially. This storyline also addresses intersectionality - in this case, how Mariana negotiates her Latina background and being raised by two moms.

As Mariana confronts the conflict brought on by the quinceañera, Lena faces some challenges of her own. The viewer learns why Lena recognizes how significant the quinceañera is to Mariana. As she tells Stef, "I understand what it's like not knowing where you belong. I've felt like that my entire life." Lena specifically refers to her biracial identity as the daughter of a black woman and a white man. A conversation between Lena and her mother, Dana (Lorraine Toussaint) at the quinceañera not only reveals Lena's feelings of alienation as a biracial woman but also offers a frank discussion of black identity. The cause of the argument is Dana's rejection of Lena's justification for the lavish party: namely, providing Mariana with an opportunity to be a part of the Latino/a community. Dana explains that in her opinion, being Latino/a is about more than "the color of her [Mariana's] skin," spelling out what is merely implied in other scenes. This assumption also fuels Mariana's fear, namely that as an adopted daughter of a biracial lesbian 
couple, neither of whom have a connection to Latino/a culture, Mariana has no claim to her Latina heritage. Lena's anger in reaction to Dana's declaration is easy to understand, as it questions Lena's parenting and also hits close to home for someone who has herself struggled with cultural belonging. Lena and Dana's lengthy argument opens up a space for a critical interrogation of black identity in contemporary culture-a space created by a strategic use of diversity for branding purposes. That is, the possibility of including such a conversation on The Fosters is at least enabled by ABC Family's desire to present their brand as inclusive of diversity.

The engagement with diversity on The Fosters is not of the "special episode" variety where an episode is dedicated to the exploration of a controversial social issue and then never mentioned again. Moreover, in contrast with Nickelodeon's ambivalent engagement with diversity - there, but not discussed-Lena and Mariana's storylines in "Quinceañera" offer numerous moments in which clear-cut definitions of cultural and familial belonging are questioned. The Fosters as a whole challenges a traditional definition of belonging, namely that one feels most at home with the culture or family into which one is born. In its stead, the place where one can belong is the "new kind of family" put forth by ABC Family's brand, inviting millennials to envision the future of family through the channel's programming and to identify the channel itself as a kind of diverse family to which they as viewers can belong.

In addition to exploring issues of race and ethnicity, The Fosters offers a multifaceted take on lesbian identity and sexuality via Stef and Lena's relationship. The most surprising aspect of this complex portrayal is the acknowledgment of Stef and Lena's sex life. For a teen-oriented, prime-time soap, this is especially remarkable. The Fosters addresses a demographic for which the discussion of lesbian sex is usually considered unsuitable. Other programs, especially on network television, often gloss over the more intimate aspects of gay and lesbian relationships - for example, on Modern Family (2009-). ${ }^{39}$ While basic cable has more leeway when it comes to representing sexuality, The Fosters is constrained by its appeal to a younger audience - the program is rated TV-14, meaning it is suitable for viewers aged fourteen and up. The ongoing inclusion of scenes that remark on or show the more intimate aspects of Stef and Lena's relationship thus contribute to the meaningful diversity on the program. Other storylines centered on Stef and Lena's lesbian identities complicate some of the homonormative aspects of these characters, which include their middle-class life, their professional careers, their domesticity, and their committed relationship. The path to marriage, for example, is neither obvious nor easy for Stef and Lena.

Intimacy appears in two ways on The Fosters: in the form of establishing shots that show Stef and Lena in bed and as the topic of conversation. Regarding the former, the most memorable example is the opening shot of "The Honeymoon," an episode that led into the second half of season one after a six-month hiatus. Considering that this is the scene that welcomes viewers back to the program after a long absence, it takes on additional significance, underlining the centrality of Stef and Lena's relationship to the program. Moreover, it stresses the importance of intimacy to their relationship, as these opening shots could easily have featured them in other settings. 


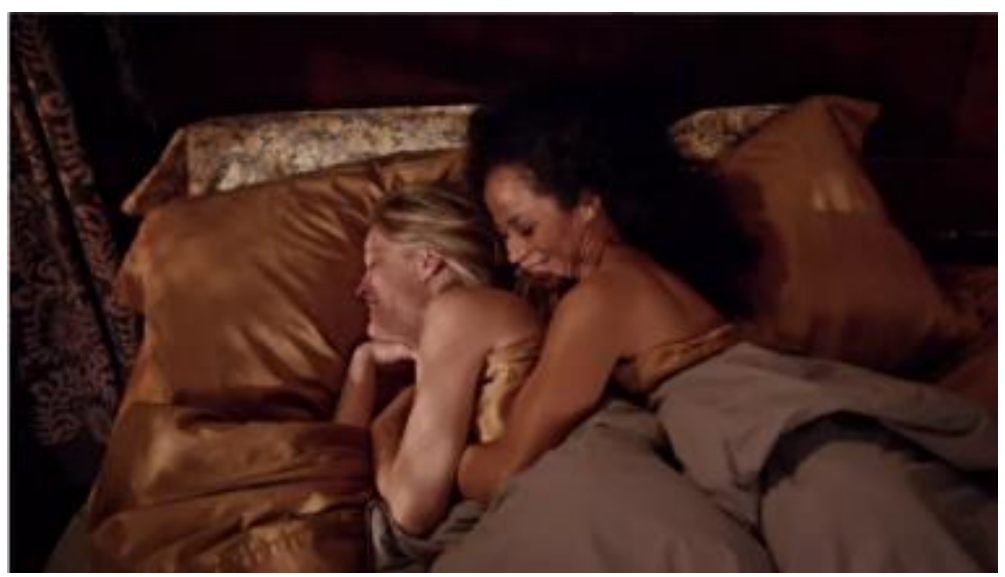

Figure 4. Screenshot from the opening scene of "The Honeymoon."

Other scenes feature conversations about sex. One of these conversations occurs after a party that Stef and Lena host. At the party, a lesbian couple who are clearly long-time friends of the Fosters share the news that they have decided to split up. ${ }^{40}$ Discussing this with Stef, Lena remarks that their friends haven't had sex for a year. When Stef can't recall the last time she and Lena had sex, Lena comments, "if you have to think about it, it's been too long." Stef cites their many obligations as a reason for their temporary lack of intimacy, but they both decide that making time for sex is important, and they schedule a date for the next day. The issue of intimacy most often comes up when it is missing from Stef and Lena's relationship. While one might think that the lack of sex in their relationship is an avoidance mechanism - a convenient way to circumvent showing intimacy-I argue that it is the opposite. By including conversations between Stef and Lena about the strain that their preoccupation with jobs and family places on their sex life (and by extension on their relationship on the whole), the significance of intimacy to a well-functioning relationship is highlighted. Additionally, the frequent shots of Stef and Lena in bed demonstrate that The Fosters does not try to avoid showing lesbian intimacy. Rather, it provides viewers with an insight that is appropriate to the parameters established by genre and target audience. The framing of intimacy as significant component of a healthy relationship also sets The Fosters apart from other cable programs that use lesbian sexuality as "edgy" or titillating element. ${ }^{41}$ On The Fosters, the inclusion of lesbian sexuality enhances the complexity of Stef and Lena's relationship and thus serves a diegetic purpose.

While all the other examples of meaningful diversity I discussed have direct ties to ABC Family's branding, the inclusion of intimacy in the representation of Stef and Lena's relationship does not have this direct connection. Showing that Stef and Lena have sex is not necessary to establish them as parents of the "new kind of family." That aspect is already established in the care and love they show their children. Branding aside, the overt address of the intimate aspects of Stef and Lena's relationship certainly furthers the inclusion of meaningful diversity in a way that is unusual for TV addressed to teens and young adults.

\section{Conclusion}

The complex representation of diversity on The Fosters challenges the conventional scholarly wisdom that mainstream commercial texts tend to offer simplistic visions of race, sexuality, gender, and class. I maintain that the commercial context and origin of The Fosters should not keep scholars from recognizing the program as an important contribution to meaningful 
diversity on contemporary television. After all, The Fosters offers the type of meaningful diversity called for by media scholars: its plot centers on an interracial lesbian couple raising adopted children of varying ethnic backgrounds. Moreover, the program features episodes that address tensions arising out of racial, sexual, and class difference. In contrast with tokenized inclusions of branded diversity on Nickelodeon or on network programming from the 1990s, The Fosters offers a sustained engagement with the process of identity formation in particular and life in an interracial queer family in general. On a broader level, ABC Family's decision to include diversity as a core feature of its millennial-oriented brand makes programming like The Fosters possible. Indeed, as my analysis of ABC Family's brand and of various story arcs from The Fosters' first season demonstrates, it is precisely ABC Family's strategic use of diversity that opens up a space for a critical interrogation of interracial and lesbian identity in contemporary culture.

1 Melanie E. S. Kohnen is a media scholar whose research focuses on how digital media challenge us to rethink diversity in relationship to cultural identities, technological infrastructures, and the media industry. She is particularly interested in how the media industry and millennial audiences understand diversity on digital entertainment platforms. Her book Queer Representation, Visibility, and Race in American Film and Television: Screening the Closet is forthcoming from Routledge (winter 2015), and her work has also appeared in several anthologies and journals, including Creative Industries and Journal of Popular Television.

2 Mary Beltrán, "Meaningful Diversity: Exploring Questions of Equitable Representations on Diverse Ensemble Cast Shows," Flow 12, no. 7 (2010).

3 The Ellen Show, March 21, 2014.

4 Suzanna Walters explains the drawbacks of equating gay and straight experiences in the following way: "When mainstream gays and their straight allies argue for the inclusion of gays because gays are no different from straights, real inclusion can never take place. ... the assimilation route eradicates the difference differences makes by rendering invisible the lived experience of being gay in a homophobic culture." All the Rage: The Explosion of Gay Visibility (Chicago: University of Chicago Press, 2003), 19.

5 Glee (Fox, 2009-2015) is a good example of this practice. Similar to The Fosters in its cast of teenage characters and millennial audience address, Glee includes characters with varying ethnic, racial, sexual, gender, and class identities, but consistently privileges the points of view of its white characters.

6 See Beltrán, "Meaningful Diversity."

${ }^{7}$ Denis Faye, "Focused on Family," Writers Guild of America, West, last modified, July 12, 2013.

8 “ABC Family Fact Sheet 2012," ABC Family, accessed July 14, 2014.

9 See, for example, Amanda Kondolojy, "'The Fosters' Renewed for Second Season by ABC Family," TV by the Numbers, last modified October 11, 2013; Errol Lewis, "ABC Family Greenlights Two New Drama Pilots," Soap Opera Network, last modified August 23, 2012; Tambay A. Obenson, “ABC Family Begins Production on Drama Pilot 'The Fosters,'” Indiewire, last modified November 7, 2012. 
${ }^{10}$ Neil Howe and William Strauss, Millennials Rising: The Next Great Generation (New York: Vintage, 2000).

${ }^{11}$ Julie Liesse, "Getting to Know the Millennials," Advertising Age, July 9, 2007: A1.

12 Cited in ibid., A4.

${ }^{13}$ Louisa Stein, introduction to Millennial/Fandom: Television Audiences in the Transmedia Age (Iowa City: University of Iowa Press, 2015).

14 Julia Himberg, "Multicasting: Lesbian Programming and the Changing Landscape of Cable TV," Television and New Media 15, no. 4 (2014): 297.

${ }^{15}$ Stein, Millennial/Fandom.

${ }^{16}$ Sarah Banet-Weiser, Kids Rule! Nickelodeon and Consumer Citizenship (Durham, NC: Duke University Press, 2007), 7.

${ }_{17}$ Nancy Giges, “TV Makeovers," Advertising Age, April 25, 2008, C94-96.

18 In her work on the Disney Channel, Jennifer Gillan argues that the channel's short form content and programming engages controversial social issues by offering "ideological counterpoints." For example, the Disney Channel offers the optimistic self-branding millennial who makes YouTube videos as a counterpoint to labor anxieties and the impact of economic recession. See Jennifer Gillan, Television Brandcasting: The Return of the Content-Promotion Hybrid (New York: Routledge, 2014). Similar to this, ABC Family offers "a new kind of family" to counter conservative family values.

${ }^{19}$ Untitled post by Inspiration Cocoa, last modified June 16, 2014.

${ }^{20}$ For scholarly work on these channels, see Arlene Dávila, Latinos, Inc.: The Marketing and Making of a People (updated ed., Berkeley: University of California Press, 2012), especially chapter 5; Anthony Freitas, "Gay Programming, Gay Publics: Public and Private Tensions in Lesbian and Gay Cable Channels," in Cable Visions, ed. Sarah Banet-Weiser, Cynthia Chris, and Anthony Freitas (New York: NYU Press, 2007), 21533; and Jennifer Fuller, "Branding Blackness on U.S. Cable Television," Media, Culture, and Society 32, no. 2 (2010): 285-305, among others.

${ }^{21}$ Newer broadcast networks like Fox and UPN also used cable TV-inspired narrowcasting as a strategy to gain a foothold in the television industry in the late 1980s and late 1990s, respectively. Both broadcasters focused on African American audiences through sitcoms and other programming, but dropped attention to this group of viewers once they managed to reach the coveted white male 18-49 demographic. See Kristal Brent Zook, Color by Fox: The Fox Network and the Revolution of Black Television (Oxford: Oxford University Press, 1999).

22 Banet-Weiser, Kids Rule!, 145.

${ }^{23}$ Ibid., 146, 171.

${ }^{24}$ See, for example, Alyssa Rosenberg, "ABC Family President Michael Riley Says Diversity Key to Millennial Audiences," Think Progress, last modified January 9, 2012; Sarah Caldwell, "The Fosters," Entertainment Weekly, June 14, 2013; Margaret Lyons, "Vulture TV Awards: The Year's Best Teen Show Is The Fosters," Vulture, last modified June 17, 2014; Christopher Rudolph, "Watch: Groundbreaking Series Tackles Gay Misconception in an Awesome Way," Huffington Post, last modified August 1, 2013.

${ }^{25}$ Ron Becker, Gay TV and Straight America (New Brunswick, NJ: Rutgers University Press, 2006), 95. 


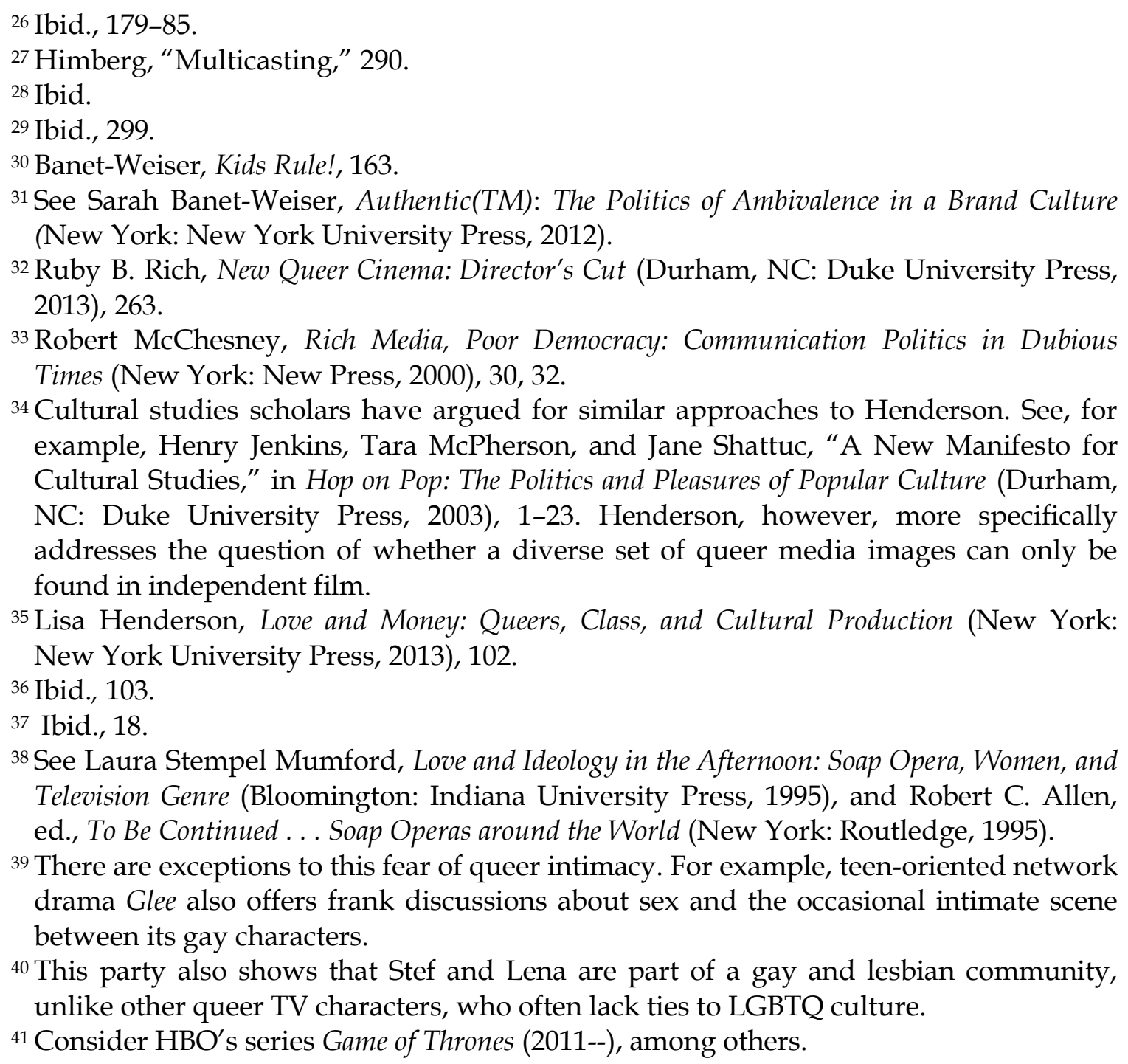

\section{Bibliography}

Allen, Robert C., ed. To Be Continued. . . Soap Operas around the World. New York: Routledge, 1995.

Banet-Weiser, Sarah. Kids Rule! Nickelodeon and Consumer Citizenship. Durham, NC: Duke University Press, 2007.

- - - Authentic(TM): The Politics of Ambivalence in a Brand Culture. New York: New York University Press, 2012.

Becker, Ron. Gay TV and Straight America. New Brunswick, NJ: Rutgers University Press, 2006.

Beltrán, Mary. "Meaningful Diversity: Exploring Questions of Equitable Representations on Diverse Ensemble Cast Shows." Flow 12, no. 7 (2010).

Dávila, Arelene. Latinos, Inc.: The Marketing and Making of a People. Updated ed. Berkeley: University of California Press, 2012. 
Freitas, Anthony. "Gay Programming, Gay Publics: Public and Private Tensions in Lesbian and Gay Cable Channels." In Cable Visions, edited by Sarah Banet-Weiser, Cynthia Chris, Anthony Freitas, 215-33. New York: New York University Press, 2007.

Fuller, Jennifer. "Branding Blackness on U.S. Cable Television." Media, Culture, and Society 32, no. 2 (2010): 285-305.

Gillan, Jennifer. Television Brandcasting: The Return of the Content-Promotion Hybrid. New York: Routledge, 2014.

Henderson, Lisa. Love and Money: Queers, Class, and Cultural Production. New York: New York University Press, 2013.

Himberg, Julia. "Multicasting: Lesbian Programming and the Changing Landscape of Cable TV." Television and New Media 15, no. 4 (2014): 289-304.

Howe, Neil, and William Strauss. Millennials Rising: The Next Great Generation. New York: Vintage, 2000.

McChesney, Robert. Rich Media, Poor Democracy: Communication Politics in Dubious Times. New York: New Press, 2000.

Mumford, Laura Stempel. Love and Ideology in the Afternoon: Soap Opera, Women, and Television Genre. Bloomington: Indiana University Press, 1995.

Stein, Louisa. Millennial Fandom: Television Audiences in the Transmedia Age. Iowa City: University of Iowa Press, 2015.

Walters, Suzanna Danuta. All the Rage: The Explosion of Gay Visibility. Chicago: University of Chicago Press, 2003.

Zook, Kristal Brent. Color by Fox: The Fox Network and the Revolution of Black Television. Oxford: Oxford University Press, 1999.

\section{$(c c)$ BY-NC-ND}

Copyright (c) 2015 (Melanie E. S. Kohnen). Media Industries is an open-access, peer-reviewed, online academic journal. As such, we aim to participate in the open exchange of information. This work is licensed under a Creative Commons Attribution Noncommercial No Derivatives (by-nc-nd) License. Under this license, this work is available for sharing and noncommercial distribution provided the appropriate attribution is given. 